\author{
REVIEW ARTICLE \\ AFRICAN JOURNAL OF CLINICAL AND EXPERIMENTAL MICROBIOLOGY. JANUARY 2014 ISBN 1595-689X VOL15 No.1 \\ AJCEM/1322 \\ COPYRIGHT 2014 http://dx.doi.org/10.4314/ajcem.v15i1.8 \\ AFR. J. CLN. EXPER. MICROBIOL. 15(1): 48-50 \\ http://www.ajol.info/journals/ajcem
}

\title{
GUT FERMENTATION SYNDROME
}

\author{
*Fayemiwo, S.A. and Adegboro, B. \\ Departments of Medical Microbiology , College of Medicine, University College Hospital, Ibadan, Nigeria and Bingham \\ University, Karu, Nasarawa State, Nigeria. \\ *Correspondence: Dr Fayemiwo, S.A., Department of Medical Microbiology\& Parasitology, University College Hospital, \\ Ibadan, Nigeria. E-mail- dayteet@yahoo.com
}

\begin{abstract}
Fungi have not been recognized to cause such notable syndromes until very recently. It has been documented among few individuals who became intoxicated after consuming carbohydrates, which became fermented in the gastrointestinal tract. These claims of intoxication without drinking alcohol, and the findings on endogenous alcohol fermentation are now called Gut Fermentation Syndrome. This review will concentrate on understanding the aetiology, clinical manifestations, laboratory diagnostic options and treatment of the syndrome.
\end{abstract}

KEYWORDS: Gut Fermentation Syndrome, Fungi, Yeast, Saccharomyces cerevisiae.

\section{INTRODUCTION}

Infectious diseases physicians are familiar with several syndromes associated with bacterial and parasitic diseases. Examples of such are rheumatic fever, rheumatic heart disease, and acute glomerulonephritis (following Lancefield group A streptococcal infections); toxic shock syndrome, Ritter's disease and scalatiniform rash (following infections by Staphylococcus aureus); Reiter's disease (following infections by Chlamydia trachomatis) (1). Fungi have not been recognized to cause such notable syndromes until very recently.

\section{RECENT FINDINGS}

Kaji and others described the case of a 24 years old female who became intoxicated after consuming carbohydrates, which fermented in the gastrointestinal tract (2). In this situation the causative organisms were determined by cultures to be Candida albicans and Candida krusei.

Claims of endogenous fermentation of this type have been used as a defense against drunken driving charges (3).

Most bacteria that ferment sugars do so through glycolytic, pentose phosphate and Entner- Doudoroff pathways, with lactic and pyruvic acids as their major end products (4). Common yeasts (C. albicans, C. tropicalis and Torulopsis glabrata) and Saccharomyces cerevisiae are able to ferment sugars through the homolactic, heterolactic or mixed acid fermentation pathways, with ethanol as the major end product (4). Candida is common yeast found in the environment, on our bodies and in our bodies. It competes for space with the normal flora on the skin and in warm and moist environments especially digestive tract. Candida can overgrow almost anywhere in the body and cause an infection. Candida species are the most common cause of invasive fungal infections in humans, producing infections that range from nonlife threatening mucocutaneous disorders to invasive disease that can involve any organ.

Because of the claims of intoxication without drinking and the findings on endogenous alcohol fermentation, a new syndrome called Gut Fermentation Syndrome was described (5). This syndrome also goes by several other names, such as Auto-Brewery Syndrome, Syndrome A and Endogenous Ethanol Fermentation (5). The underlying mechanism is thought to be an overgrowth of yeast in the gut whereby the yeast ferments carbohydrates into ethanol.

Gut Fermentation Syndrome is a relatively unknown phenomenon in modern medicine. The earliest cases of this phenomenon were described prior to 1976 and only a few cases have been reported in the last three decades $(2,6$,$) .$

Dahshan and Donovan (7) described the case of a 13 years old girl with short gut syndrome who became intoxicated after ingesting carbohydrates. She had been placed in a rehabilitation facility with no access to alcohol. Aspirates from her small intestines grew Candida glabrata and Saccharomyces cerevisiae. 
Barbara Cordell and Justin McCarthy (5) presented a case study of a 61 years old male with a welldocumented case of Gut Fermentation Syndrome verified with glucose and carbohydrate challenges. The stool cultures demonstrated the causative organism as Sacharomyces cerevisiae.

\section{DIAGNOSTIC PROCEDURES}

A clinical test was proposed in 1990 for dietary fermentation (8). Subjects suspected of gut fermentation syndrome were given a fasting glucose challenge of $5 \mathrm{gm}$ glucose orally. One gram of glucose was given in a hardened gelatin capsule to ensure passage into the duodenum. Blood glucose and ethanol levels were measured at 1 hour. Fasting blood alcohol levels were zero in nearly all normal subjects; but $61 \%$ of the 510 subjects showed an increase in blood alcohol levels on the average of $2.5 \mathrm{mg} / \mathrm{dl}$ (range 1.0 - $7.0 \mathrm{mg} / \mathrm{dl}$ ). This compared to near zero blood alcohol levels in the control group given the same challenge (8).

Another experiment was also conducted by combining five infant food formulas and/or supplements with four common yeasts (C. albicans, C. tropicalis, Torulopsis glabrata, and $S$. cerevisiae) to measure ethanol production in vitro. All of the mixtures of yeast and carbohydrate produced ethanol, with the Saccharomyces. cerevisiae preparations being the highest (9). Saccharomyces cerevisiae, also known as brewer's yeast, has a very well-known history and life cycle because of the

\section{REFERENCES}

1. Adegboro, B. Some Clinical Syndromes in Microbiology. Chapter in: Microbiology, Ed. Boaz Adegboro. Ibadan University Press. 1st Edition 2010. Ibadan, Nigeria.

2. Kaji, H., Asanuma, Y., Ide V, Saito N. , Hisamura, M., Murao, M., Yoshida, V. and Takahashi, K., "The Auto-Brewery Syndrome-The Repeated Attacks of Alcoholic Intoxication Due to the Overgrowth of Candida (Albicans) in the Gastrointestinal Tract," Materia Medica Polona, Vol. 4, No. 29, 429-435.

3. Logan B.K, Jones A.W ."Endogenous ethanol 'auto-brewery syndrome' as a drunk-driving defence challenge. Medicine, science, and the law." July 2000 Retrieved 2013-02-27.

4. Adegboro, B. Some Important Biochemical Pathways by Microbes. In: Microbiology, Ed. Boaz Adegboro. Ibadan University Press. 1 ${ }^{\text {st }}$ Edition 2010. Ibadan, Nigeria. brewing industry. More recently the entire genome of $S$. cerevisiae has been identified due to its important use in fermenting corn into ethanol for fuel consumption.

S. cerevisiae has mostly been identified as a pathogen in critically ill patients who are immunocompromised $(10,11)$. Not one single article could be found on an $S$. cerevisiae infection in an otherwise healthy, immuno-competent adult (5).

\section{MANAGEMENT OF PATIENTS}

Individuals with this syndrome should be given an oral course of fluconazole $100 \mathrm{mg}$ daily for three weeks followed by a course of Nystatin 500,000 IU 4 times daily for three weeks. Acidophilus tablets could also be given to re-colonize the gut (5). These antifungal drugs tend to put an end to the condition.

\section{CONCLUSION}

Gut Fermentation Syndrome, also known as AutoBrewery Syndrome, Syndrome A and Endogenous Ethanol Fermentation, is a recently described clinical condition amongst patients who feel drunk after a heavy carbohydrate meal. The underlying mechanism is an overgrowth of yeast in the gut whereby the yeast ferments carbohydrates into ethanol. Oral antifungal chemotherapy, given for at least three weeks is the treatment of choice. Further studies are needed to improve our understanding of the pathogenesis of this syndrome and definitive diagnostic procedure(s).

5. Barbara Cordell and Justin McCarthy. A Case Study of Gut Fermentation Syndrome (AutoBrewery) with Saccharomyces cerevisiae as the Causative Organism. International Journal of Clinical Medicine, 2013, 4, 309-312.

6. IwataK., "A Review of the Literature on Drunken Syndromes Due to Yeasts in the Gastrointestinal Tract," University of Tokyo Press, Tokyo, 1972, 260-268.

7. Dahshan A. and DonovanK., "Auto-Brewery Syndrome in a Child with Short Gut Syndrome: Case Report and Review of the Literature," Journal of Pediatric Gastroenterology and Nutrition, 2001, Vol. 33, No. 2, 214- 215.

8. Hunnisett A. and HowardJ., "Gut Fermentation (or the 'Auto-Brewery') Syndrome: A New Clinical Test with Initial Observations and Discussion of Clinical and Bio- chemical Implications," Journal of Nutritional Medicine,1990 Vol. 1, No. 1, 33-39.

9. Bivin W. and Heinen, B., "Production of Ethanol from Infant Food Formulas by 
Common Yeasts," Journal of Applied Bacteriology, 1985, Vol. 58, No. 4, 355-357.

10. Riquelme A., CalvoM.,Guzman, A., et al., "Saccharomyces cerevisiae Fungemia after Saccharomyces boulardii Treatment in Immunocompromised Patients," Jour- nal of Clinical Gastroenterology, Vol. 36, No. 1, , 4143.
11. Olver, W., James S., Lennard A,, Galloway A., RobertsT., BoswellT. andRussellN., "Nosocomial Transmission of Saccharomyces cerevisiae in Bone Marrow Transplant Patients," Journal of Hospital Infection, 2002, Vol. 52, No. 4, 268-272. 